\title{
Comprehensive identification and expression analysis of $B$-Box genes in cotton
}

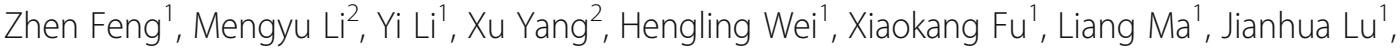 \\ Hantao Wang ${ }^{1 *}$ and Shuxun $Y u^{1 *}$
}

\begin{abstract}
Background: B-BOX (BBX) proteins are zinc-finger transcription factors with one or two BBX domains and sometimes a CCT domain. These proteins play an essential role in regulating plant growth and development, as well as in resisting abiotic stress. So far, the BBX gene family has been widely studied in other crops. However, no one has systematically studied the $B B X$ gene in cotton.

Results: In the present study, 17, 18, 37 and 33 BBX genes were detected in Gossypium arboreum, G. raimondii, G. hirsutum and G. barbadense, respectively, via genome-wide identification. Phylogenetic analysis showed that all BBX genes were divided into 5 main categories. The protein motifs and exon/intron structures showed that each group of $B B X$ genes was highly conserved. Collinearity analysis revealed that the amplification of BBX gene family in Gossypium spp. was mainly through segmental replication. Nonsynonymous (Ka)/ synonymous (Ks) substitution ratios indicated that the $B B X$ gene family had undergone purification selection throughout the long-term natural selection process. Moreover, transcriptomic data showed that some GhBBX genes were highly expressed in floral organs. The qRT-PCR results showed that there were significant differences in GhBBX genes in leaves and shoot apexes between early-maturing materials and late-maturing materials at most periods. Yeast two-hybrid results showed that GhBBX5/GhBBX23 and GhBBX8/GhBBX26 might interact with GhFT. Transcriptome data analysis and qRTPCR verification showed that different GhBBX genes had different biological functions in abiotic stress and phytohormone response.
\end{abstract}

Conclusions: Our comprehensive analysis of BBX in G. hirsutum provided a basis for further study on the molecular role of GhBBXs in regulating flowering and cotton resistance to abiotic stress.

Keywords: G. hirsutum, BBX, flower bud differentiation, phytohormone, stress response

\footnotetext{
*Correspondence: w.wanghantao@163.com; ysx195311@163.com

'State Key Laboratory of Cotton Biology, Institute of Cotton Research of CAAS, Anyang 455000, China

Full list of author information is available at the end of the article
}

(c) The Author(s). 2021 Open Access This article is licensed under a Creative Commons Attribution 4.0 International License, which permits use, sharing, adaptation, distribution and reproduction in any medium or format, as long as you give appropriate credit to the original author(s) and the source, provide a link to the Creative Commons licence, and indicate if changes were made. The images or other third party material in this article are included in the article's Creative Commons licence, unless indicated otherwise in a credit line to the material. If material is not included in the article's Creative Commons licence and your intended use is not permitted by statutory regulation or exceeds the permitted use, you will need to obtain permission directly from the copyright holder. To view a copy of this licence, visit http://creativecommons.org/licenses/by/4.0/. The Creative Commons Public Domain Dedication waiver (http://creativecommons.org/publicdomain/zero/1.0/) applies to the data made available in this article, unless otherwise stated in a credit line to the data. 


\section{Background}

Zinc-finger transcription factors are a kind of vital proteins, which play essential roles in plant growth and development, as well as in response to environmental stimuli $[1,2]$. B-BOX $(\mathrm{BBX})$ protein is one of zinc-finger transcription factors, which have attracted increased amounts of attention in recent years because of its various functions. BBX proteins are characterized by one or two conserved BBX domains at their $\mathrm{N}$-terminus and sometimes a CCT domain at their C-terminus. BBX domains play an important role in transcriptional regulation and protein-protein interactions $[3,4]$. The CCT domain is involved in transcriptional regulation and nuclear transport [5-7]. In Arabidopsis, 32 BBX proteins have been identified. According to the existence of BBX domain and CCT domain, these members can be divided into five subgroups [3]. A growing body of evidence also shows that BBX proteins play a crucial role in flowering $[8,9]$, abiotic stress responses [10] and hormonal signaling networks[4].

$C O / A t B B X 1$ was the first BBX gene studied in Arabidopsis; this gene controlled flowering time by regulating the expression of downstream Flowering Locus $T(F T)$ gene [11-13]. Flowering is significantly delayed in $C O$ mutant plants, while overexpression of $C O$ could make plants flower early $[14,15]$. Other $B B X$ genes subsequently discovered, such as $B B X 4, B B X 6, B B X 7$, and $B B X 32$, could also regulate flowering time [16-19]. The mutant plants of $B B X 4$ flower earlier than wild plants, indicating that $B B X 4$ can delay the flowering of plants [16]. The mutant plants of $B B X 7$ could also flower earlier, and the plants with overexpression of $B B X 7$ showing the phenotype of delayed flowering [17]. The overexpression of $B B X 6$ could make the plant flower earlier [19]. Overexpression of $B B X 32$ showed the opposite phenotype, which could delay the flowering of the plant [18].

BBX proteins also participate in abiotic stress responses and hormone signaling networks. For example, compared with the wild type, the overexpression of $B B X 24$ in Arabidopsis had higher salt tolerance, and the root length of $B B X 24$ transgenic plants increased significantly under high-salinity conditions [20]. In Chrysanthemum, overexpression $C m B B X 24$ not only prolonged flowering time, but also enhanced cold and drought resistance [13]. $B B X$ genes also play a role in phytohormone signal transduction. $A t B B X 18$ is a positive regulator of the gibberellin (GA) signaling pathway. Molecular and phenotypic studies have shown that $B B X 18$ promotes hypocotyl growth by increasing bioactive gibberellin levels [21]. While $B B X 20$ is a negative regulator of brassinolide signal pathway. It promotes hypocotyl growth by directly binding $B Z R 1$ and inhibiting its expression [22].

Cotton is an important cash crop species. Although members of the $B B X$ family have been identified in
Arabidopsis, tomato, pear, and apple [3, 23-25], no comprehensive study of $B B X$ genes in cotton has been reported so far. With the release of the cotton genome[26], we can more systematically study the hypothetical functions of $B B X$ genes in cotton. In the present study, we made a comprehensive analysis of the physical and chemical properties, chromosome distribution, collinearity, gene structures, cis-acting elements and expression patterns of the $B B X$ gene family in G. arboreum, G. barbadense, G. hirsutum and G. raimondii. This research provided basic data for further study on the function of $B B X$ genes in cotton.

\section{Results}

Identification, chromosomal distribution and subcellular localization of $B B X$ gene family

To identify the $B B X$ genes in the Gossypium spp. genome and obtain their sequences, a global search of the Gossypium spp. genomes were carried out by using HMM profiling of the BBX domain (PF00643). After ensuring that the identified members contained conserved domains and deleted the repeated sequences, in total, of 17, 18, 37 and 33 putative BBX sequences were identified in G. arboreum, G. raimondii, G. hirsutum and G. barbadense, respectively, via genome-wide identification analysis. In $G$. hirsutum, $1 B B X$ was located on scaffold fragments. The $B B X s$ were named according to their location on the chromosomes (Fig. 1), and the BBXs located on the scaffold fragments in G. hirsutum is finally named. Table S2 contained detailed location information. The lengths of putative GaBBX protein sequences ranged from 163 aa (GaBBX3) to 374 aa (GaBBX13); GrBBXs, 197 aa (GrBBX16) to 374 aa (GrBBX10); GhBBXs, 166 aa (GhBBX29) to 374 aa (GhBBX32) and GbBBXs, 136 aa (GbBBX3) to 505 aa (GbBBX27). The predicted MW and $\mathrm{pI}$ of each BBX were shown in Table S2. The results of subcellular localization showed that all of the $B B X s$ were located in the nucleus, indicating that the nucleus was the main region of biological functions of $B B X s$.

Based on the genomic location information of 105 $B B X$ genes, we visualized the chromosome distribution of $G a B B X s, G r B B X s, G h B B X s$ and $G b B B X s$ (Fig. 1). In G. arboreum, $17 \mathrm{GaBBXs}$ were unevenly distributed on 10 chromosomes. A12 and A13 contained 3 GaBBXs, whereas the other 8 chromosomes, A01, A02, A04, A05, A06, A08, A09 and A11, contained 1 or 2 GaBBXs. In G. raimondii, $18 \mathrm{GrBBXs}$ were located on 9 chromosomes. D02 and D08 contained the most GrBBXs (3), while the other 6 chromosomes contained only 1 or 2 GrBBXs. In G. hirsutum, $37 \mathrm{GhBBXs}$ were unevenly mapped to 21 chromosomes, while, GhBBX37 was located on unassembled scaffolds. At13 contained 4 GhBBXs. At01, Dt01, Dt12 and Dt13 contained 3 $G h B B X s$, and the other 16 chromosomes contained 


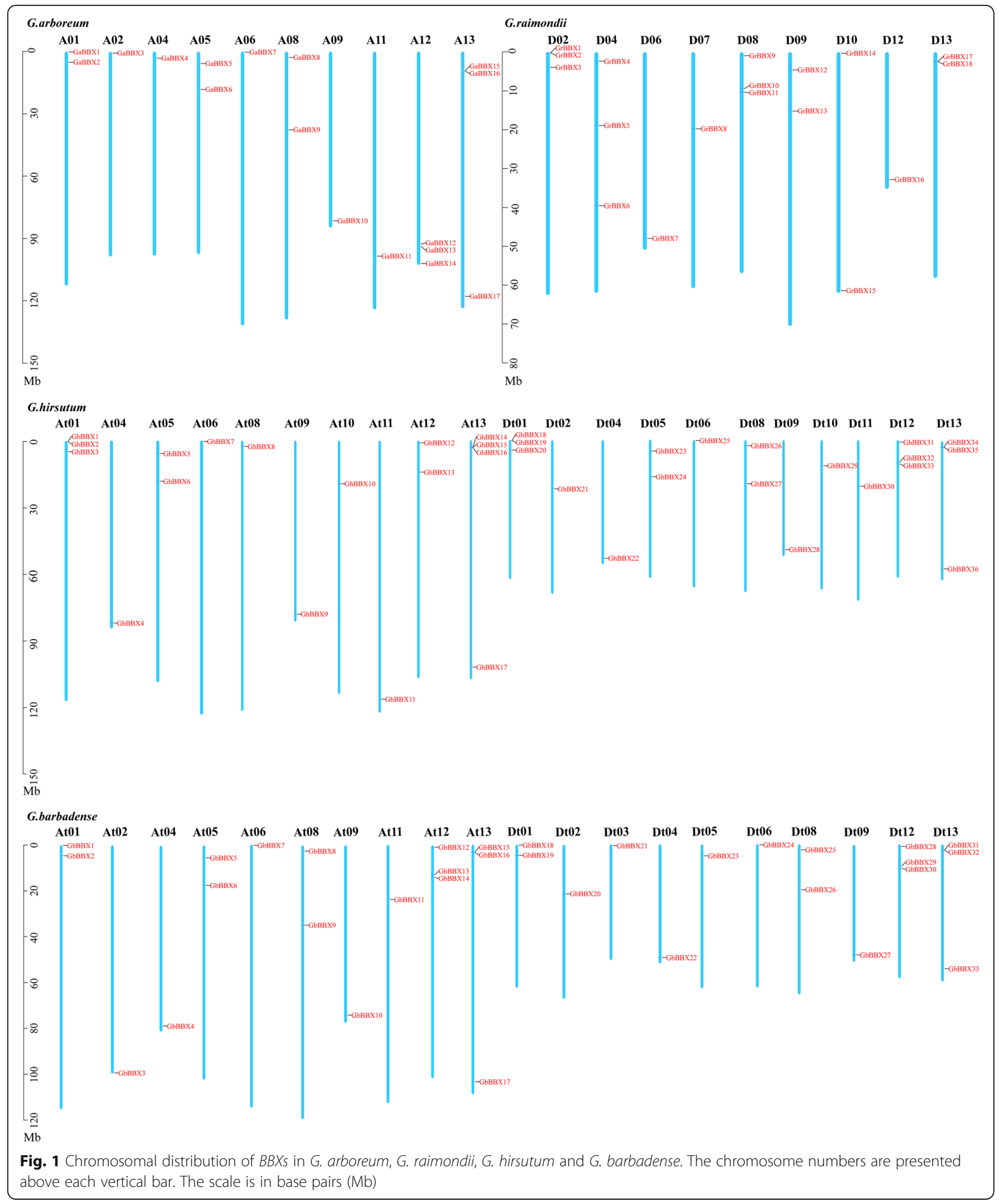

only 1 or 2 GhBBXs. In G. barbadense, 33 GrBBXs were unevenly mapped to 20 chromosomes. At12, At13, Dt12 and Dt13 contained 3 GrBBXs. The other 16 chromosomes contained only 1 or $2 \mathrm{GrBBXs}$.
Phylogenetic analysis of the $B B X$ gene family

To investigate the phylogenetic relationships of $B B X s$, 137 BBX protein sequences (G. arboreum (17), G. raimondii (18), G. hirsutum (37), G. barbadense (33) and A. 
thaliana (32)) were used to construct a phylogenetic tree based on the NJ method. Members of the $B B X$ family were classified into 5 major groups, I-V (Fig. 2), and each subgroup was named according to the taxonomic results of previous studies in Arabidopsis [4]. It was worth noting that although AtBBX26 and AtBBX27 belonged to group $\mathrm{V}$ of Arabidopsis according to their structural classification, they were phylogenetically closer to $A t B B X 12$ and $A t B B X 13$, which were in group II. As shown in Fig. 2, group II was the smallest subgroup, containing $7 B B X s$. By contrast, group IV had the most massive numbers of $B B X$ genes, including $69 B B X s$. There were $29 B B X s$ in group I. No cotton species were divided into group III or group V. In G. hirsutum, $B B X$ gene had 2, 9 and 26 members in group II, I and IV, respectively.

\section{Replication events of $B B X$ gene family}

From the perspective of the cotton evolution, tetraploid cotton is the result of genome doubling of two diploid cotton hybrids. In terms of the number of genes, the sum of $B B X$ genes in G. arboreum (17) and G. raimondii (19) was about equal to the number of those in G. hirsutum (37) or G. barbadense (33). The results further confirmed this view. To explore the replication events of the $B B X$ gene family, MCScanX was used to analyze the collinearity between the $A_{t}$ and $D_{t}$ subgenomes of G. hirsutum and their corresponding ancestral A and D diploid genomes (Fig. 3). The data showed that most homologous gene pairs of the $B B X$ gene family were amplified by segmental replication, which meant segmental replication played a key role in the evolution of the $B B X$ gene family. However, the genomic evolution of allotetraploid cotton is extremely complex. In the process of evolution, the genome has experienced not only segmental duplication events but also many tandem duplication events. The duplicate types of $B B X s$ in G. hirsutum were shown in detail in Table S3. In G. arboretum and G. raimondii, 1 and 2 tandem duplication events (GaBBX15/GaBBX16 as well as GrBBX1/ GrBBX2 and $G r B B X 17 / G r B B X 18)$ were identified, respectively. In $G$. hirsutum, 4 tandem duplications

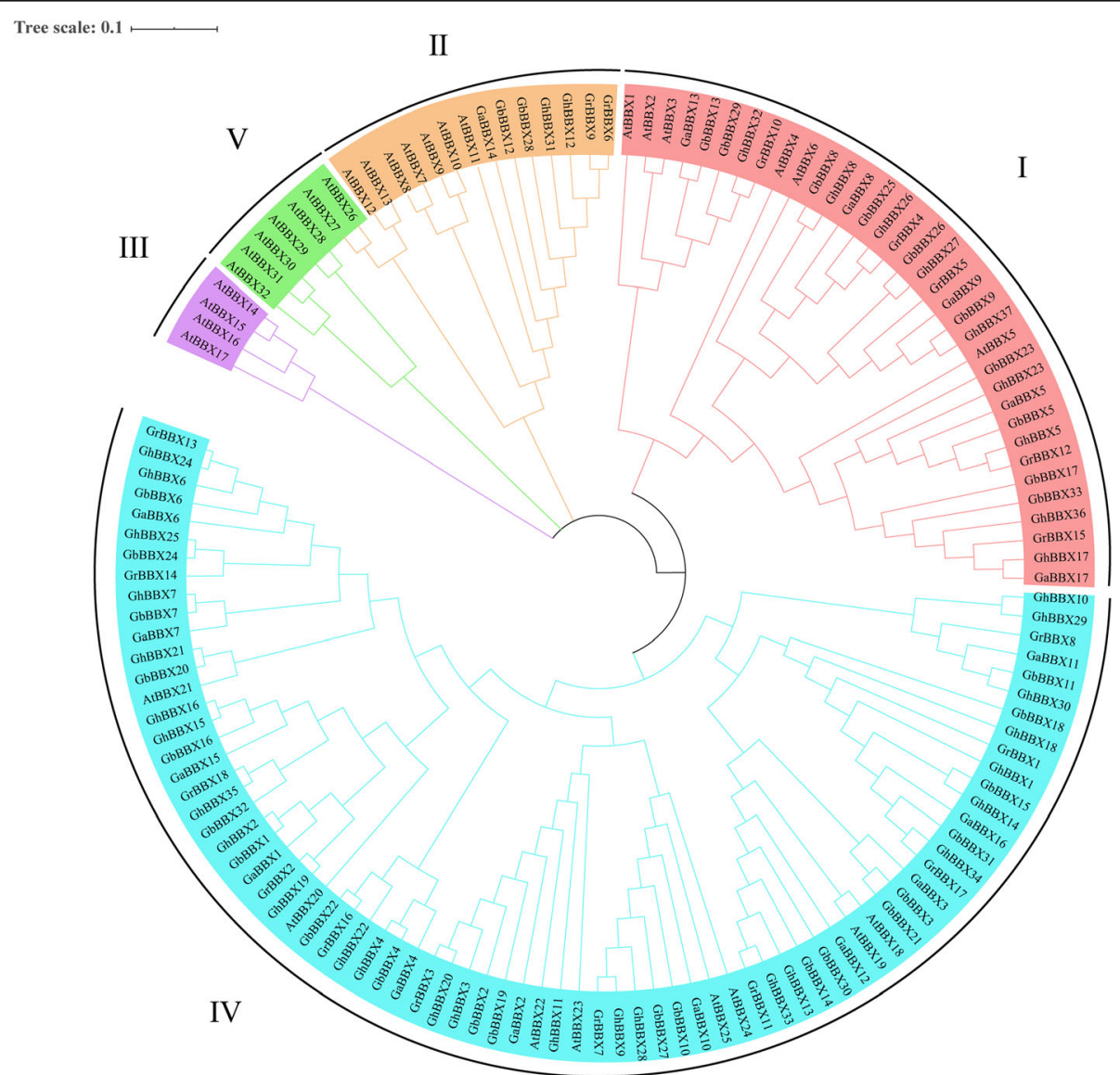

Fig. 2 Phylogenetic tree of BBX proteins. The sequences of 105 BBX proteins of G. raimondii, G. arboreum, G. hirsutum, G. barbadense and A. thaliana (shown here) were aligned with ClustalX version 2.0, and a phylogenetic tree was generated by Mega 7.0 software using the NJ method with 1000 bootstrap replicates. Different colors present the five subfamilies of BBXs 


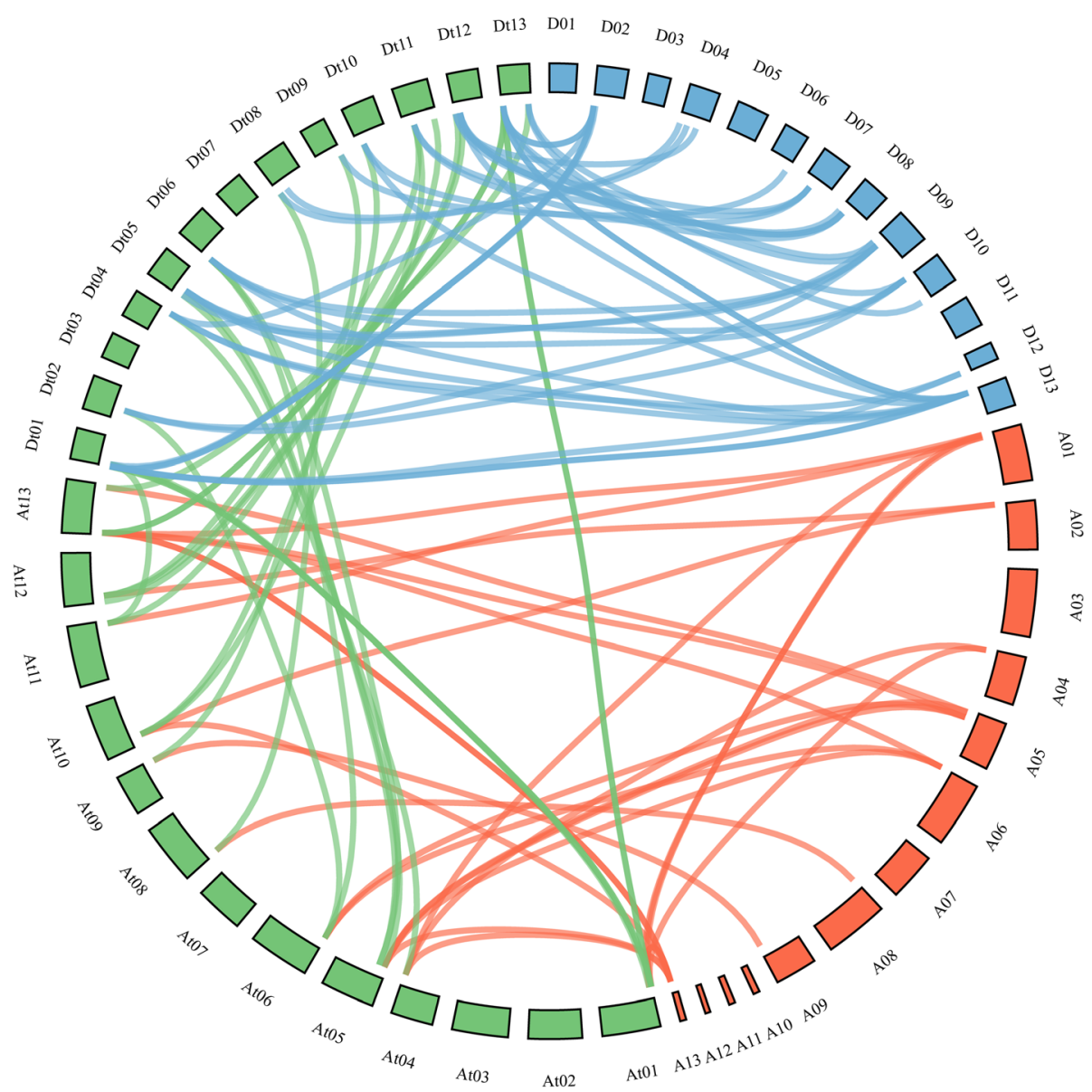

Fig. 3 Genome-wide synteny results of BBX genes from G. arboreum, G. raimondii, and G. hirsutum. The red lines present linked gene pairs between $G$. arboreum and G. hirsutum. The blue lines present linked gene pairs between G. raimondii and G. hirsutum, and the green lines present linked gene pairs between $G$. hirsutum (A and D subgenomes)

(GhBBX1/GhBBX2, GhBBX15/GhBBX16, GhBBX18/ GhBBX19, GhBBX34/GhBBX35) were discovered.

$K a / K s$ ratios were calculated to evaluate the selection pressure of these homologous gene pairs. Among the 95 homologous gene pairs, 90 homologous gene pairs had $K a / K s$ values $<1$, which indicated that most of the homologous gene pairs had undergone purifying selection in the process of evolution, and these genes pairs might play a similar function. Only a few homologous gene pairs had experienced positive selection, which might lead to new biological functions of these genes.

\section{Analysis of gene structure and conservative motif}

The results of the phylogenetic analysis showed that 37 GhBBXs could be divided into 5 groups (A-E), which contained 9, 2, 12, 5 and 9 members, respectively (Fig. 4I). To better understand the structural characteristics of $G h B B X s$, the exon/intron structure was analyzed by GSDS (Fig. 4III). The GhBBX genes contained 3 to 7 exons, but most of them contained less than 5 exons.
Moreover, the conserved motif was further analyzed by MEME program. The GhBBXs in the same group showed similar motif composition, which further validated the classification results (Fig. 4II). Except for group A, the order of motif 1 and motif 2 in GhBBX of other groups was the same. Motif 3 existed only in group A and group B, but motif 4 existed in all groups except group A and group B. Motif 5 existed only in group C, while motif 6 only existed in group E. Figure 4 showed that the distribution of conserved motif and exon/intron structure were different among different groups, but they were highly conservative on the same branches. The results showed apparent conservation, which laying a foundation for functional conservatism and providing guidance for follow-up functional research.

\section{Analysis of cis-acting elements in GhBBX promoter regions}

To better understand the regulation of GhBBXs gene transcription and expression, the promoter region of 


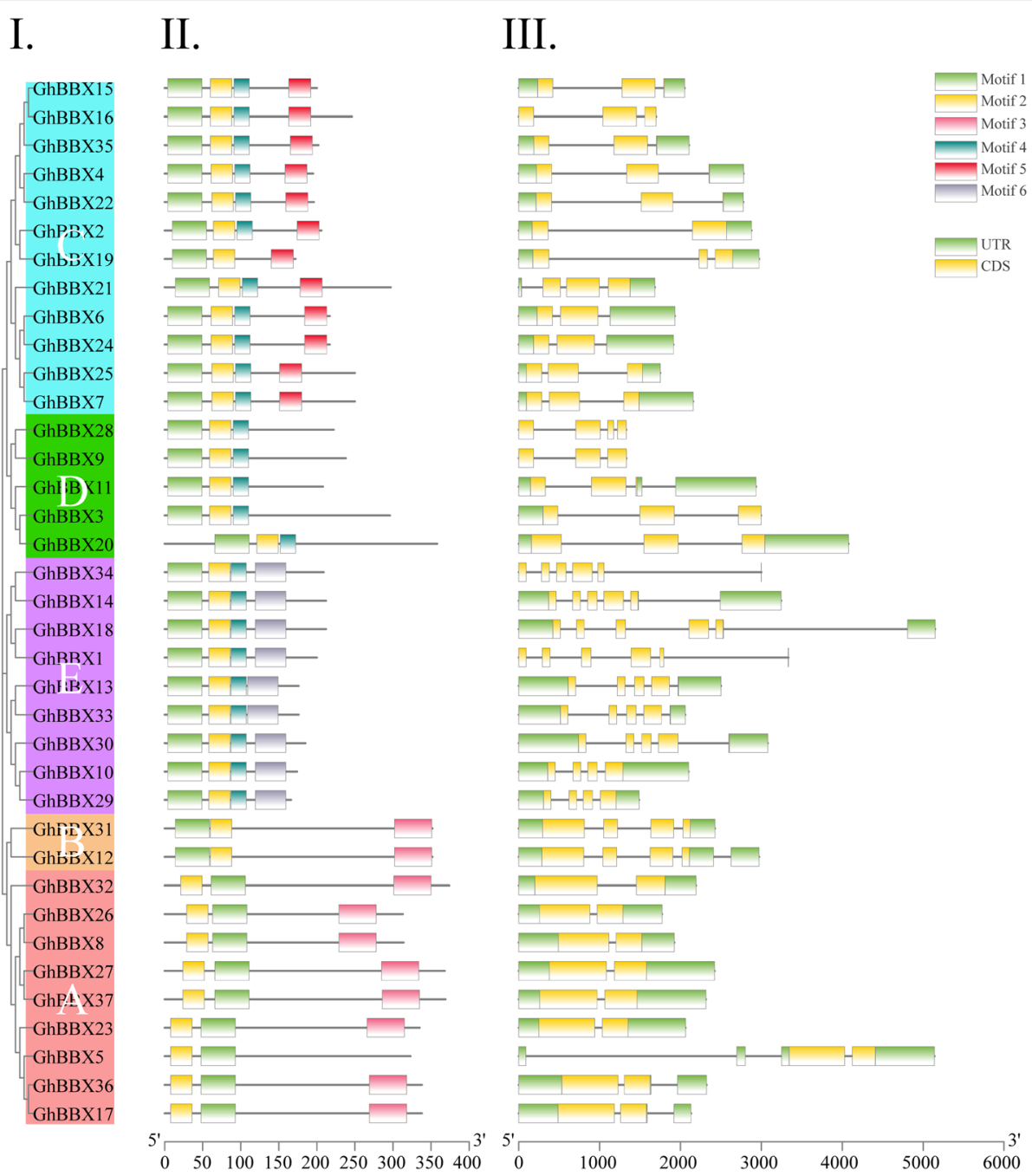

Fig. 4 Gene structure and conserved protein motifs of GhBBXS. (I) NJ phylogenetic tree analysis of G. hirsutum. A-E represent the five subgroups. (II) Shown is the distribution of the predicted motifs in the GhBBX genes. (III) Shown are the number, length, and position of exons and introns within GhBBX genes. The boxes present exons, and the black lines present introns

GhBBX (genomic DNA sequence $2 \mathrm{~kb}$ upstream of the transcription start site) were used to search the PlantCARE database. A variety of cis-elements were found in the $G h B B X$ promoter region. Among the cis-acting elements, the cis-acting elements related to phytohormone and stress response were the focus of our attention. We found abscisic acid (ABA) response element, gibberellin (GA) response element, auxin (IAA) response element, salicylic acid (SA) response element and methyl jasmonate (MeJA) response element in $21,19,11,17$ and 17 GhBBX promoters, respectively. In some $G h B B X$ promoters, there were cisacting element related to multiple phytohormone, while in other $G h B B X$ promoters, there were only cis-acting element related to a single phytohormone response. In terms of stress-related response elements, these cis-acting elements were mainly related to low temperature, drought, anaerobic and other defenses. In the midst of these elements, the anaerobic cis-acting element was the most frequent stress response element, which appeared in the promoters of 32 $G h B B X$ genes, followed by the cis-acting element in response to low temperature. It existed in the promoters of 20 GhBBX genes. Thus, it could be seen that GhBBX might respond to stress response and abiotic stress of cotton. In addition, a large number of light response elements were found in the promoter region of GhBBXs, including Box-4, G-box, GT1-motif, TCT-motif and MRE.

\section{Expression patterns of GhBBXs in different tissues}

In order to study the expression pattern of GhBBXs in different tissues, we analyzed the transcriptomic data of root, stem, leaf, anther, filament, pistil and petal in TM-1. The results showed that different members of the cotton 


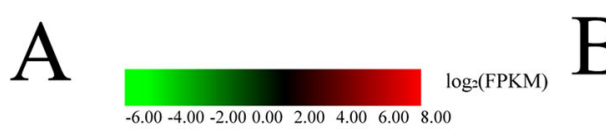
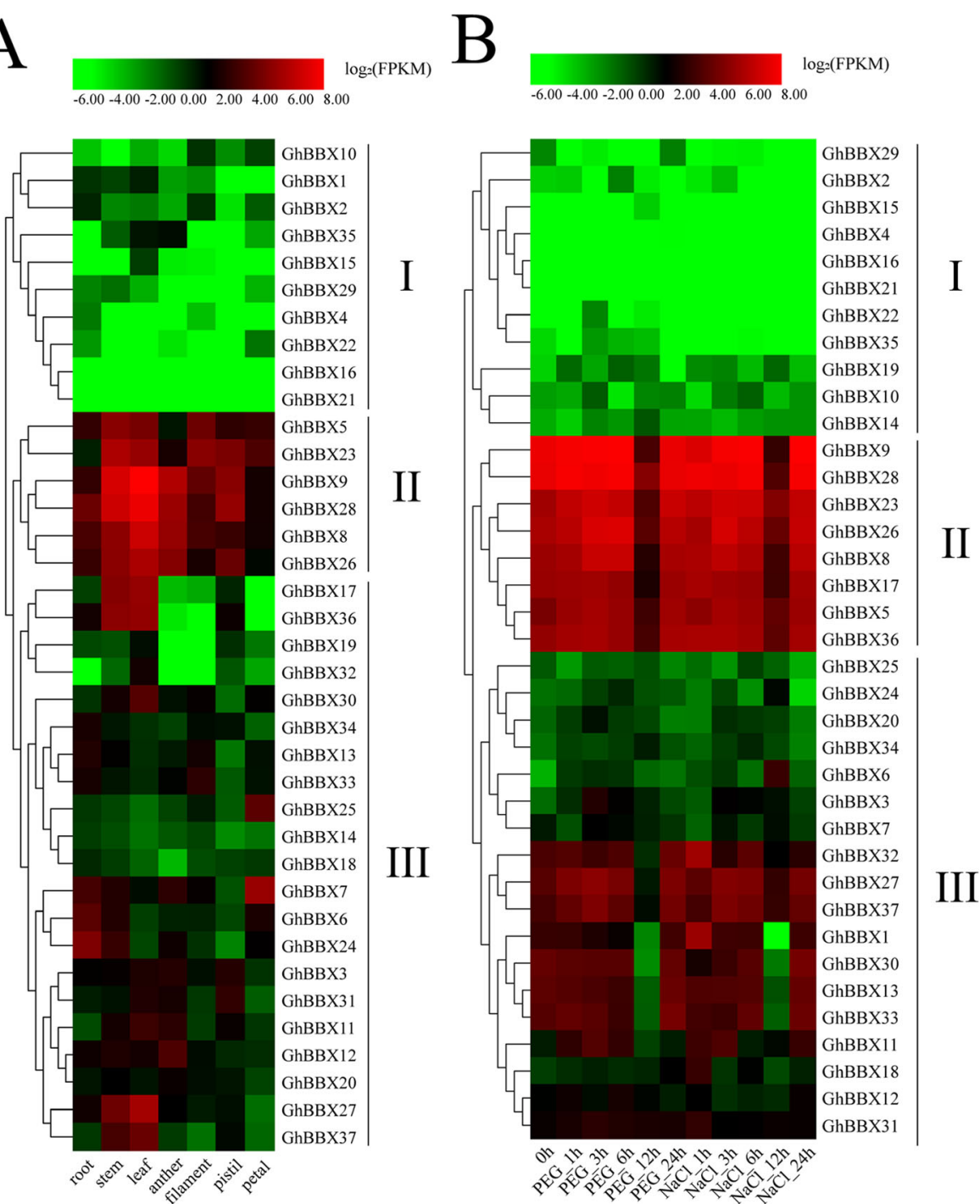

Fig. 5 Expression profiles of GhBBXs in different tissues $(\mathbf{A})$ and response to different stresses $(\mathbf{B})$. The tissues or treatments are shown at the bottom, the genes are shown on the right, and the phylogenetic relationships are shown on the left

BBX family showed different expression patterns. According to the expression characteristics and based on hierarchical clustering analysis, 37 GhBBXs were divided into 3 categories (I-III) (Fig. 5). 6 GhBBXs (GhBBX5, 8, 9, 23 26 , and 28 ) belonging to group II were highly expressed in nearly all tissues. 10 GhBBXs (GhBBX2, 4, 10, 16, 19, 21, $22,29,32$ and 35 ) belonging to group I were poorly expressed in all tissues. The remaining members (GhBBX1, 3, 6, 7, 11, 12, 13, 14, 15, 17, 18, 20, 24, 25, 27, $30,31,33,34,36$ and 37 ) belonging to group III exhibited slightly higher expression in vegetative organs, while others showed slightly higher expression in floral organs. These differences in expression patterns might be related to the various functions of GhBBXs.

\section{Expression characterization of GhBBXs in cotton flower bud differentiation}

Flower bud differentiation is an important sign that a plant is undergoing a transition from vegetative growth to reproductive growth [27]. To explore whether GhBBX gene, which was highly expressed in flower organs, was involved in the process of flower bud differentiation, we analyzed the relative expression of these genes in the leaf and shoot apex of the early-maturing cotton cultivar CCRI50 and late-maturing cotton cultivar GX11 from one-leaf stage to five-leaf stage. The graphical representation of the expression profiles of 6 genes in the leaf and shoot apex at 5 different times was shown in Fig. 6 . In the leaf, the expression levels of these six genes in the three-leaf stage and five-leaf stage of early-maturing 


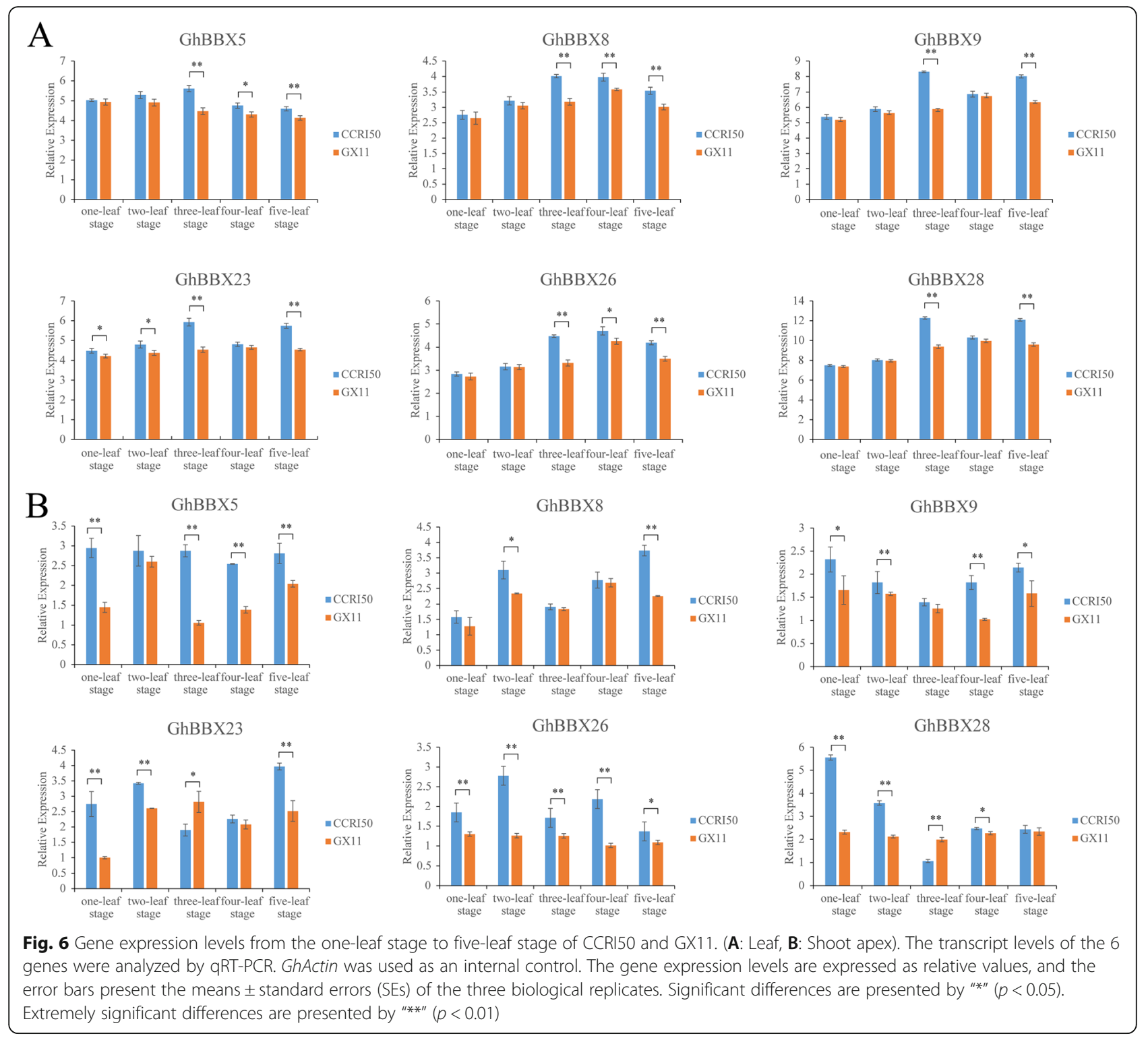

materials were higher than those of late-maturing materials, and showed a significant difference. There was a difference in the expression of GhBBX5, GhBBX8 and $G h B B X 26$ between early-maturing materials and latematuring materials at four-leaf stage, but in one-leaf stage and two-leaf stage, only the expression of GhBBX23 was different between early-maturing materials and latematuring materials, there was no significant difference in the expression of the other five genes. In the shoot apex, the expression levels of GhBBX5, GhBBX8, GhBBX9, and $G h B B X 26$ in the early-maturing material were higher than those in the late-maturing material, and significant or extremely significant differences were detected at $4,1,3$, and 5 periods, respectively. The expression levels of the other 2 genes, GhBBX23 and GhBBX28, in the early-maturing material were higher than those in the late-maturing materials at the most stages, but at three-leaf stage, the expression levels in the early-maturing material were lower than those in the late-maturing material.

GhBBXs interact with key genes in cotton flowering pathway The previous studies showed that GhFT, GhSOC1, GhLFY and GhAP1 might be key factors in cotton flowering pathway [28-31]. In order to explore the interaction of GhBBXs with key regulatory factors in flowering pathway, we selected $G h B B X 5, G h B B X 8$, GhBBX9, GhBBX23, GhBBX26 and $G h B B X 28$ to detect their interaction with GhFT, GhSOC1, GhLFY and GhAP1 by yeast two-hybrid assay. The results showed that $G h B B X 5, G h B B X 8, G h B B X 23$ and $G h B B X 26$ could 


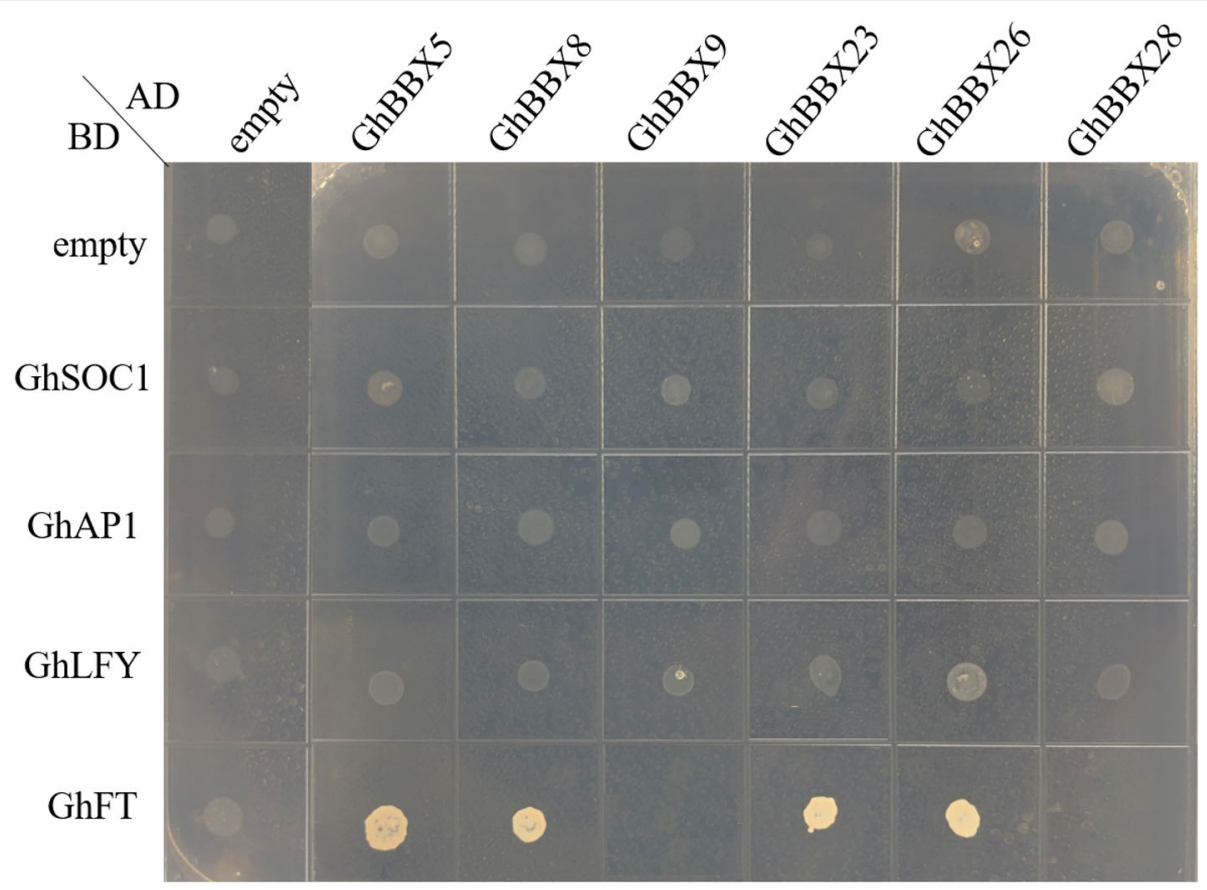

Fig. 7 Yeast two-hybrid assay of interaction between six GhBBXs and GhFT, GhSOC1, GhLFY and GhAP1. Yeast cells were co-transformed with recombinant PGADT7 and pGBKT7 vectors and grew on the SD-Trp/-Leu/-His/-Ade/ medium

interacte with GhFT. At the same time, there was no interaction between these genes and GhSOC1, GhAP1 and GhLFY (Fig. 7). Therefore, the results suggested that some members of $G h B B X s$ regulated the flowering time by interacting with $G h F T$.

\section{Expression pattern of GhBBXs under multiple stress}

The analysis of cis-acting elements in the promoter region showed that GhBBXs might be related to the abiotic stress, and some studies have shown that $B B X$ genes play a positive role in abiotic stress resistance [23, 32]. Therefore, based on the transcriptomic data of TM-1, we further analyzed the expression patterns of $G h B B X$ under PEG and $\mathrm{NaCl}$ stresses. The results showed that GhBBXs clustered mainly into three categories (I-III) based on a hierarchical clustering analysis according to expression features (Fig. 5B). The GhBBX genes that belonged to groups II and III responded to PEG and $\mathrm{NaCl}$, especially at $12 \mathrm{~h}$ after treatment, showing significantly downregulated expression. 11 GhBBXs belonging to group I showed universally low expression after stress treatment.

Based on the transcriptomic data, GhBBX5, GhBBX8, GhBBX9, GhBBX17, GhBBX23, GhBBX26, GhBBX28 and $G h B B X 36$ which belonged to group II and whose expression levels increased after stress treatment, were selected for qRT-PCR verification. As shown in Fig. 8, PEG stress affected the activity of GhBBXs. GhBBX5, $G h B B X 23$ and $G h B B X 28$ responded to PEG treatment at $1 \mathrm{~h}$, after which their expression was downregulated continuously until a minimum point was reached at $12 \mathrm{~h}$. Afterwards, their expression increased at $24 \mathrm{~h}$. The expression of $G h B B X 8, G h B B X 9, G h B B X 17$ and $G h B B X 26$ increased at the beginning, after which it decreased but then increased again. The minimum expression level occurred at $12 \mathrm{~h}$. GhBBX36 was the only gene whose expression abruptly decreased but then increased, followed by a sudden increase after reaching the minimum at $12 \mathrm{~h}$. Under $\mathrm{NaCl}$ stress treatment, GhBBX5, GhBBX8, GhBBX9, GhBBX17, GhBBX23, GhBBX26 and GhBBX36 showed the same expression pattern. The expression of these genes quickly decreased but then increased. Afterwards, their expression reached a minimum at $12 \mathrm{~h}$ followed by an increase. GhBBX28 was the only gene whose expression began at $9 \mathrm{~h}$, after which it decreased; after reaching a minimum at $12 \mathrm{~h}$, the expression increased. Taken together, the results showed that GhBBXs could respond to plant abiotic stresses, and at the same time, it provided potential candidate genes for further study.

\section{Expression pattern of GhBBXs under phytohormone}

In order to study the response of GhBBXs to phytohormone, 9 genes containing corresponding hormoneresponse elements in their promoters were selected for qRT-PCR experiment to further analyze the transcript levels of $B B X$ genes under three different hormone treatments (Fig. 9). After treated with ABA (Fig. 9 A), the expression of most of these genes increased early (mainly 


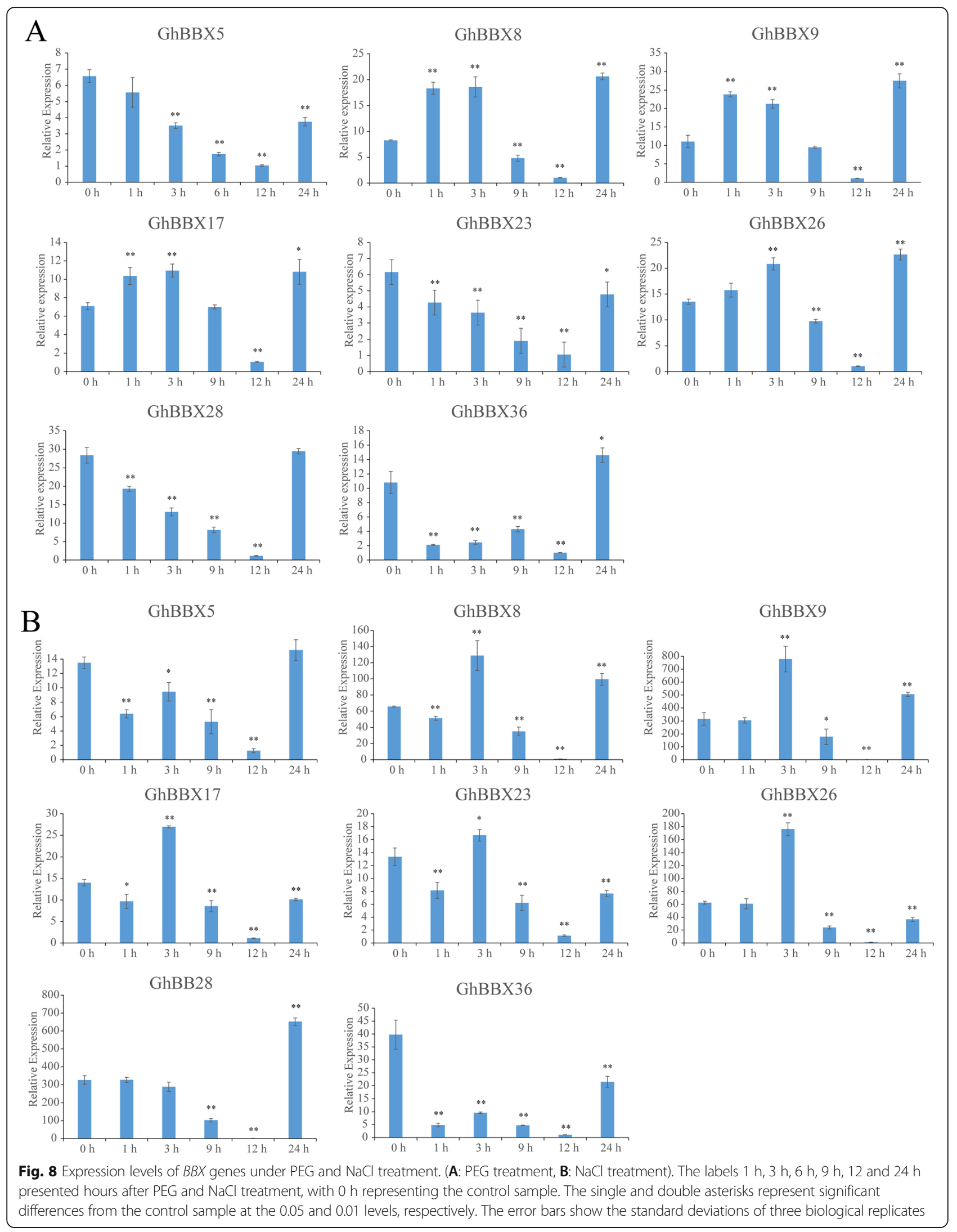




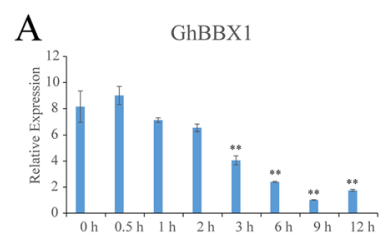

GhBBX11
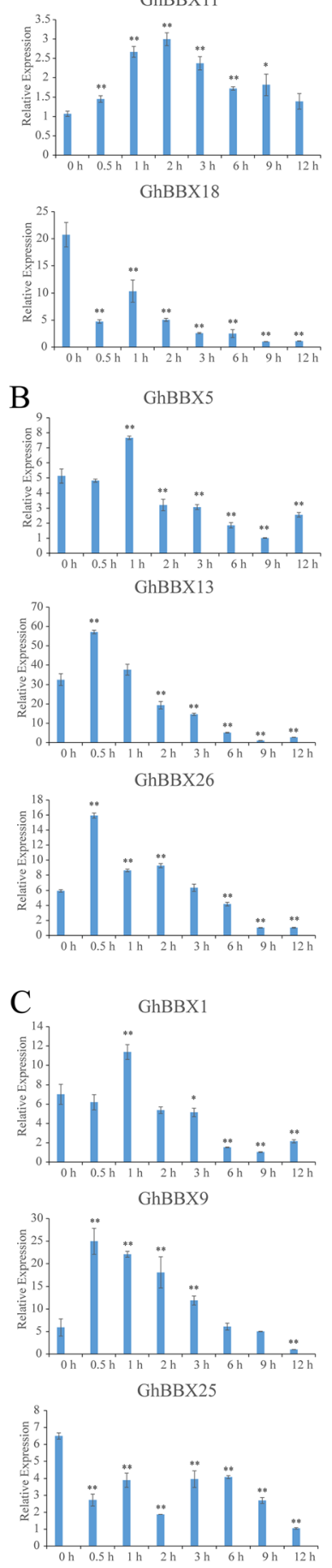

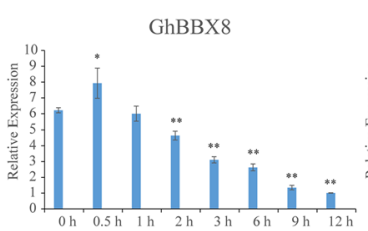

GhBBX13
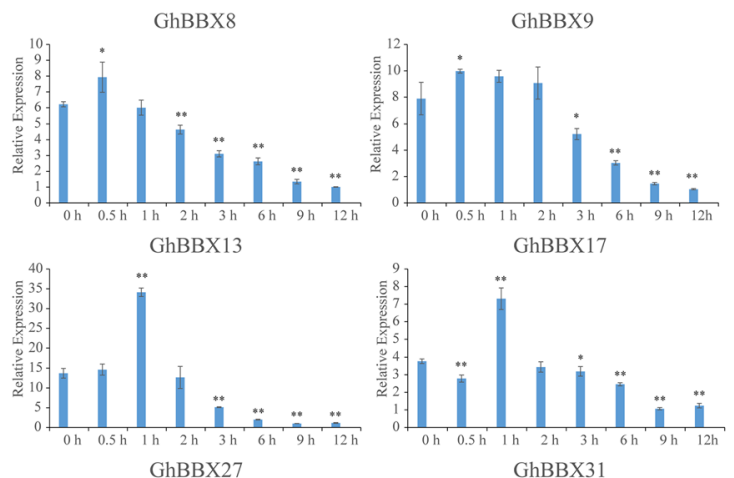

GhBBX17
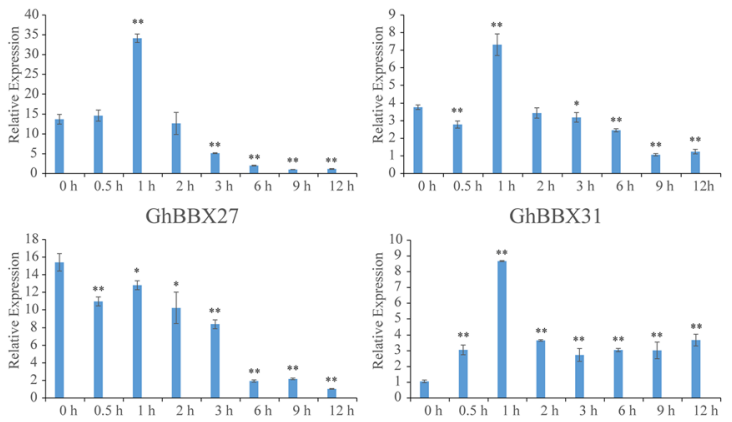

GhBBX7

GhBBX11

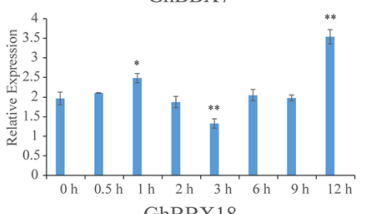

GhBBX18
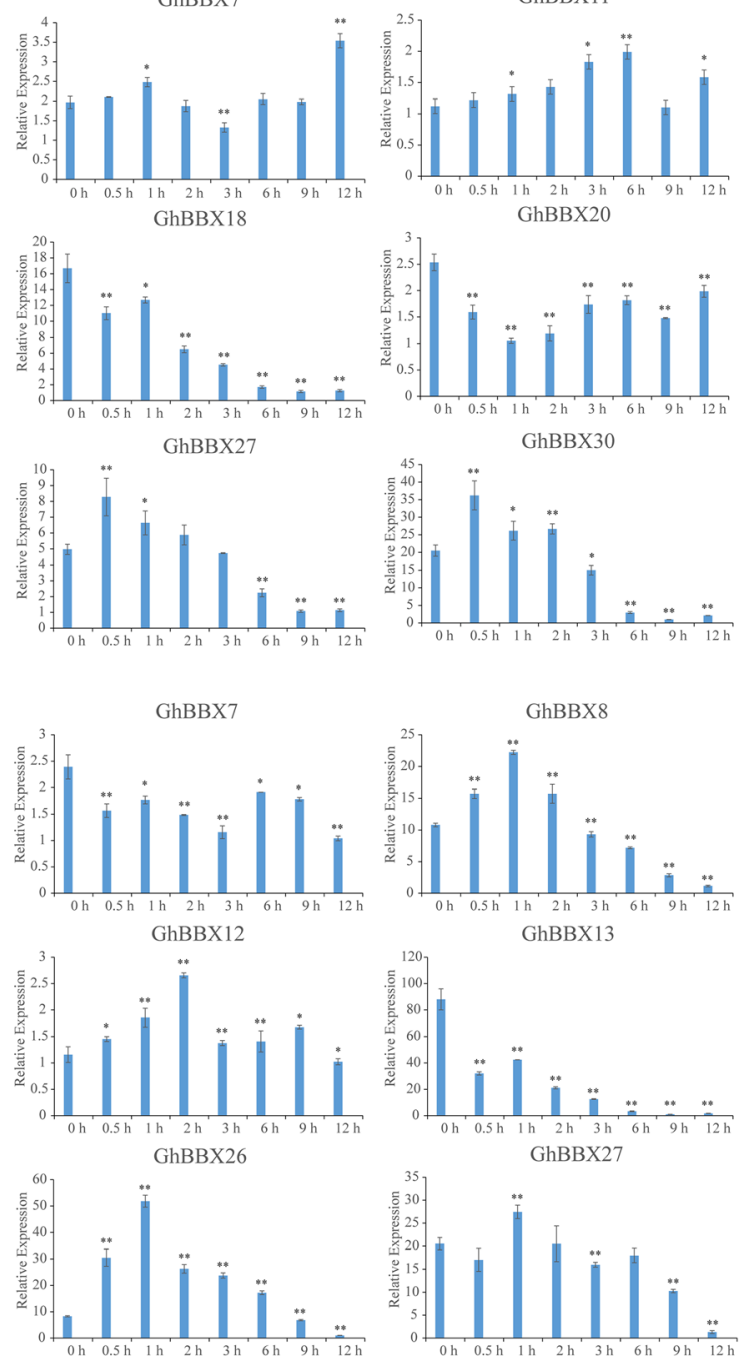

Fig. 9 (See legend on next page.) 
(See figure on previous page.)

Fig. 9 Expression profiles of $B B X$ genes in cotton plants treated with exogenous hormones in hydroponic culture. (A: $5 \mu M$ ABA treatment B: $5 \mu M$ GA treatment C: $5 \mu \mathrm{M}$ IAA treatment) The labels $0.5 \mathrm{~h}, 1 \mathrm{~h}, 2 \mathrm{~h}, 3 \mathrm{~h}, 6 \mathrm{~h}$, and $12 \mathrm{~h}$ indicate the time (hour) after treatments. The single and double asterisks represent significant differences from the control sample at the 0.05 and 0.01 levels, respectively. The error bars show the standard deviations of three biological replicates

from 0.5 to $2 \mathrm{~h}$ ), followed by a decrease. The expression of three genes decreased early, after which it increased and finally decreased with time. Under GA treatment (Fig. 9B), 4 expression patterns were found. the expression of most of these genes increased early, peaking at 0.5 or $1 \mathrm{~h}$ after GA application, after which their expression decreased over time. The expression of two genes (GhBBX18 and $G h B B X 20)$ was downregulated at all time points, and the expression of one gene, GhBBX11, was upregulated at all time points except the $9 \mathrm{~h}$ time point. The expression of GhBBX7 was upregulated early on, after which it decreased and then increased. In response to IAA treatment (Fig. 9 C), these genes could be divided into 2 major patterns on the basis of their expression characteristics. The expression of most of these genes increased early, followed by a decrease, peaking from 0.5 to $2 \mathrm{~h}$. Three genes (GhBBX7, GhBBX13 and GhBBX25) presented downregulated expression at all time points, reaching a minimum at $12 \mathrm{~h}$.

\section{Discussion}

\section{Expansion of $B B X$ genes in cotton}

Polyploidization is the primary mechanism of species formation and plant adaptation to the external environment [33]. The allotetraploid species G. hirsutum has undergone many gene duplication events, and the number of genes has increased throughout in the whole evolutionary process, which make it a perfect plant species to study the formation of polyploid in the whole evolutionary process $[34,35]$. G. hirsutum is an allotetraploid $\mathrm{AD}$ genome composed of $\mathrm{A}$ genome and $\mathrm{D}$ genome. The diploid cotton of A genome is mainly distributed in Asia and Africa, and the cotton of D genome is mainly distributed in America. The AD genome is formed by 1.5 million years of natural hybridization and chromosome doubling of the A genome and the D genome [26]. In this study, in total, $17,18,37$ and 33 putative $B B X$ sequences were identified in G. arboreum, G. raimondii, G. hirsutum and G. barbadense, respectively, via genome-wide analysis. The sum of $B B X$ genes in $G$. arboreum (17) and G. raimondii (19) was about equal to the number of those in G. hirsutum (37). Collinearity analysis showed that most homologous gene pairs of the $B B X$ gene family were amplified by segmental replication, which meant segmental replication was the main way for the $B B X$ gene family to evolve.

\section{Conservation and evolutionary of $B B X$ genes}

The conservation of biological function was based on the conservation of structural sequences. We analyzed the conservative motifs and exon/intron structure of $G$. hirsutum, and classified it according to the conservative structure. As shown in Figs. 4 and $9 G h B B X$ members were classified into class A, and two $G h B B X$ members were classified into class $B$. All the members in these two categories contained two BBXs plus the CCT domain. The remaining $26 G h B B X$ members carried both B-BOX1 and B-BOX2, which could be divided into C, D and $\mathrm{E}$ class according to their gene structure and motif. The remaining 2 domains, B-BOX1 and BOX1 plus CCT, which appeared in Arabidopsis did not exist in cotton. To sum up, the gene composition of these GhBBX was similar to that of Arabidopsis and there were also differences. We speculated that the loss of the other two gene structures in upland cotton might be caused by evolution.

In the process of evolution, it must be under the pressure of natural selection. We calculated the $\mathrm{Ka} / \mathrm{Ks}$ ratio between the At and Dt subgenomes of G. hirsutum and their corresponding ancestral A and D diploid genomes to evaluate the selection pressure of homologous genes pairs (Table S3). The results showed that the $K a / K s$ values of most $B B X$ homologues gene pairs were less than 1 . Therefore, we speculated that most of the $B B X$ genes had been purified selection throughout the longterm evolutionary, resulting in segmental replication, which might cause the gene to maintain its original function unchanged.

\section{Cis-acting elements of $B B X s$ in $G$. hirsutum}

Promoters play an essential role in the regulation of plant gene expression. In this study, we extracted the promoter sequence of $2 \mathrm{~kb}$ upstream of the transcriptional initiation site of GhBBXs and statistically analyzed the cis-acting elements. As shown in Table S4, we identified a variety of stress-related cis-acting elements in the cotton $B B X$ gene promoter, and we speculated that $G h B B X$ genes might be related to a variety of external stresses. The result of the qRT-PCR experiment showed that the genes containing these cis-acting elements related to stress enabled plants to respond quickly and regulate the expression of related genes after PEG and salt treatment, so as to avoid further harm to plants. We speculated that they might enhance the resistance to 
environmental stress by enhancing their resistance to stress in G. hirsutum. At the same time, five hormone response elements were identified in cotton $B B X$ gene promoter, and some genes containing cis-acting elements of ABA, GA and IAA were tested by qRT-PCR experiment. The results showed that the expression of genes containing hormone response elements changed in different degrees after dredging the corresponding hormone treatment. The promoters of some $B B X$ genes contained more than one hormone-responsive cis-acting element. We speculated that these genes might participate in hormone signal transduction and act as transcriptional regulators. Their expression might be regulated by a variety of plant hormones.

\section{Potential roles of GhBBX genes in G. hirsutum}

An increasing number of studies have shown that $B B X$ genes are involved in many aspects such as plant growth and development, as well as in resisting abiotic stress. TM-1 expression profiles were used to evaluate the expression patterns of $37 G h B B X$ genes in different cotton tissues and after external stress treatment. They were classified according to their expression abundance in the transcriptome, which might reflect genes in the same group might have similar functions. The results will provide strong data support for the study of specific genes.

$B B X$ genes are involved in the flowering pathway. In Arabidopsis, BBX6/COL5 promoted flowering by increasing the expression of $F T$ under short-day conditions [19], while $B B X 7 / C O L 9$ negatively regulates flowering by inhibiting the expression of $C O$ and $F T$ [17]. BBX32/EIP6 might inhibit flowering probably in a way independent of $C O$ [36]. According to our findings, $G h B B X 8$ and $G h B B X 26$ were the closest homologues of $A t B B X 6$ in cotton and the expression level in flower organs was significantly higher than that in other organs. Moreover, these genes clustered together with the other

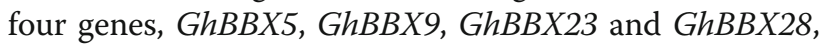
in a heat map of tissue expression specificity. Therefore, we speculated that these genes might be related to flowering. Flowering is closely related to flower bud differentiation and early maturity of cotton. The qRT-PCR experiment results showed, these genes presented significant differences in the leaf and shoot apex of the early-maturing material CCRI50 and the late-maturing material GX11 from one-leaf stage to five-leaf stage at most periods. We validated the interaction of some members of GhBBXs with key factors in the cotton flowering pathway by yeast two-hybrid. The results showed that $G h B B X 5, G h B B X 8, G h B B X 23$ and $G h B B X 26$ could interact with GhFT. Preview studies have showed that overexpression of GhFT in Arabidopsis could lead to early flowering of transgenic plants [28]. Taken together, we speculated that $G h B B X$ gene could regulate the flowering time by interacting with GhFT.

$B B X$ gene is also involved in stress signal transduction. In Arabidopsis, BBX24 was involved in signal transduction in response to salt stress. Compared with wild-type Arabidopsis plants, Arabidopsis plants overexpressing $B B X 24$ were more salt-tolerant [20]. The results of qRTPCR experiment showed that most $B B X$ family genes began to be expressed at $1 \mathrm{~h}$ after abiotic stress. This rapid response mechanism could protect plants and reduce the damage caused by abiotic stress. Moreover, the $B B X$ genes had a common feature: regardless of the changes in their expression at previous stages, the minimum expression of each occurred at $12 \mathrm{~h}$. Taken together, these results indicated the $G h B B X$ proteins played an important role in plant resistance to abiotic stress. However, the specific functions and regulatory mechanisms need to be clarified by further investigation.

\section{Conclusions}

In this study, members of the $B B X$ gene family were identified in Gossypium arboreum, G. raimondii, G. hirsutum and G. barbadense, respectively. The main purpose of our study was to explore the phylogenetic relationships, collinearity, expansion patterns, gene structures, cis-acting elements and expression patterns of the $B B X$ family. The transcription of GhBBXs in different tissues indicated that some members of GhBBXs might play a role in flower bud differentiation of cotton. The qRT-PCR results showed that there were significant differences in $G h B B X$ genes in leaves and shoot apex of early-maturing materials and late-maturing materials at most periods. Through the yeast verification of the four key genes in the flowering pathway, GhBBX and GhFT, GhSOC1, GhLFY, GhAP1, we found that GhBBX might interact with $G h F T$ to regulate the flowering time. Transcriptome and qRT-PCR analysis showed that $G h B B X$ genes were involved in the complex regulatory network of the abiotic stress response. After hormone treatment, it was found that $G h B B X$ gene might play an essential role in regulating plant growth and development by regulating a variety of hormone signal pathways. In general, genome-wide analysis of $B B X s$ has laid a solid foundation for the functional analysis of $B B X$ genes in cotton.

\section{Materials and methods} Identification of the $B B X$ gene family

The genomes sequences of G. arboretum (CRI, version 1.0), G. barbadense (HAU, version 1), G. hirsutum (HAU, version 1) and G. raimondii (JGI, version 2.1) were obtained from the CottonFGD (http://www. cottonfgd.org/) [37]. The BBX protein sequences of Arabidopsis thaliana were obtained from the TAIR website 
(https://www.arabidopsis.org/) [38]. The hidden Markov model (HMM) configuration file of the $B B X$ conservative domain (PF00643) was downloaded from the Pfam database (https://pfam.xfam.org/) [39]. HMMsearch program was used to search the $B B X s$ in cotton by using the HMM file. The threshold of E-value was $1.0 \mathrm{E}^{-10}$ [40]. The SMART database (http://smart.embl-heidelberg. de/) was subsequently used to identify whether the candidate protein sequences contain the special domain of $B B X$ family [41]. The ExPASy website (http://web.expasy.org/ protparam/) was used to predict the amino acid (aa) sequence, molecular weight (MW) and isoelectric point (pI) of the identified BBX proteins[42], and the subcellular localization was predicted through the ProtComp version 9.0 server (http://linux1.softberry.com/berry.phtml).

\section{Phylogenetic analysis and sequence alignment}

Multiple sequence alignment of BBX proteins from the four Gossypium species and Arabidopsis was performed by ClustalW. By using the MEGA 7.0 program and neighbour-joining (NJ) method, a rootless phylogenetic tree was constructed. Bootstrap replications (1000) were used to evaluate the reliability of the interior branches [43].

\section{Chromosome location and gene duplication analysis}

The physical chromosome locations of all $B B X$ genes were obtained from the genome sequence databases of the four Gossypium species, and MapChart software was used for visualization [44]. The genome replication gene pairs of G. hirsutum, G. raimondii and G. arboreum were detected by MCScanX software [45]. Circos was used to map the segmental duplication events on chromosomes [46]. TBtools was used to calculate the nonsynonymous mutation rate $(K a)$ and synonymous mutation rate $(K s)$ of $B B X$ genes replication [47].

\section{Conserved sequence and gene structure analysis}

The exon-intron structure was analyzed on the GSDS (http://gsds.cbi.pku.edu.cn/) based on inputting GFF gene annotation files [48]. The motifs of BBX protein sequences were confirmed by the MEME (http://memesuite.org/tools/meme), using the following parameters: up to six motifs, the best width of 6 to 50 [48].

\section{Promoter region cis-acting elements analysis}

The promoter sequence 2000 bp upstream of each GhBBX gene coding region was retrieved from CottonFGD (http://www.cottonfgd.org/). The predicted cis-acting elements were searched by using the PlantCARE online program (http://bioinformatics.psb.ugent.be/webtools/ plantcare/html/) [49].

\section{Gene expression pattern analysis}

The expression levels of GhBBXs in different tissues and after abiotic stress responses were obtained from previously reported transcriptome data of G. hirsutum TM-1, which were obtained from the NCBI Sequence Read Archive (SRA:PRJNA490626) (https://www.ncbi.nlm.nih. gov/bioproject/PRJNA490626) [50]. TBtools was used to draw a heat map to show the expression patterns of $G h B B X$ genes [47].

\section{Plant materials and treatments}

The early-maturing cotton cultivar CCRI50 and the latematuring cotton cultivar Guoxinmian11(GX11) were grown in the field in Anyang, Henan Province, China. Leaf and shoot apex samples were taken at one, two, three, four and five-leaf stages. The samples were collected and frozen immediately in liquid nitrogen, after which they were stored at $-80{ }^{\circ} \mathrm{C}$.

The G. hirsutum cultivar Texas Marker-1 (TM-1) was used for stress and hormone treatments of seedlings in a climate-controlled greenhouse (light/dark cycle: $16 \mathrm{~h}$ at $28{ }^{\circ} \mathrm{C} / 8 \mathrm{~h}$ at $22{ }^{\circ} \mathrm{C}$ ). The seedlings were grown in hydroponic solution $(\mathrm{pH}$ 6.2) at the four-week-old of the three-leaf stage were treated with consisting of sodium chloride $(300 \mathrm{mmol} / \mathrm{L})$, polyethylene glycol (PEG) 6000 (30\%), $5 \mu \mathrm{M}$ abscisic acid (ABA), $5 \mu \mathrm{M}$ gibberellic acid (GA) or $5 \mu \mathrm{M}$ auxin (IAA), respectively. Control plants were only treated with hydroponic solution. Leaves were harvested at $0 \mathrm{~h}, 1 \mathrm{~h}, 3 \mathrm{~h}, 9 \mathrm{~h}, 12 \mathrm{~h}, 24 \mathrm{~h}$ after stress treatments, and leaves were harvested at $0 \mathrm{~h}, 0.5 \mathrm{~h}, 1 \mathrm{~h}$, $2 \mathrm{~h}, 3 \mathrm{~h}, 6 \mathrm{~h}, 9 \mathrm{~h}$, and $12 \mathrm{~h}$ after hormone treatments. The samples were collected and frozen immediately in liquid nitrogen, after which they were stored at $-80^{\circ} \mathrm{C}$.

\section{RNA extraction and qRT-PCR analysis}

Total RNA was extracted from the collected samples using the RNA-prep Pure Plant Kit (TIANGEN, Beijing, China). Reverse transcription experiment was carried out using a PrimeScript RT Reagent Kit (Takara, Dalian, China). The gene-specific primers for qRT-PCR (Table S1) were designed with Oligo 7.0 software; G. hirsutum Actin (GhActin) was used as an internal control. qRTPCR (Promega, Madison, WI, USA) (three biological replicates) was performed on an ABI 7500 real-time PCR system (Applied Biosystems, USA). The scheme was carried out as follows: step $1,95{ }^{\circ} \mathrm{C}$ for $30 \mathrm{~s}$; step 2, 40 cycles of $95{ }^{\circ} \mathrm{C}$ for $5 \mathrm{~s}$ followed by $60{ }^{\circ} \mathrm{C}$ for $34 \mathrm{~s}$; and step 3 , melting curve analysis. The relative expression levels of GhBBXs were calculated by $2^{-\triangle \Delta C T}$ method, and statistical analyzed by T-tests.

\section{Yeast two-hybrid assay}

The full-length sequences of $G h B B X 5, G h B B X 8$, GhBBX9, GhBBX23, GhBBX26 and GhBBX28 were 
cloned into pGADT7 vector, and the coding sequences of GhFT, GhSOC1, GhAP1 and GhLFY were cloned into pGBKT7 vector with the gene-specific primers (Table S5). Different combinations of recombinant plasmids pGADT7 and pGBKT7 were co-transformed into yeast strain Y2HGold and cultured on DDO (SD/-Leu/-Trp) plate for 3 days. Three independent colonies on the DDO plate were selected and the interaction was further detected on the QDO (SD/-Leu/-Trp/-His/-Ade) plate.

\section{Supplementary information}

The online version contains supplementary material available at https://doi. org/10.1186/s12864-021-07770-4.

Additional file 1: Table S1. Primer pairs used in the $\mathrm{QRT} T-P C R$ analysis.

Additional file 2: Table S2. Detailed physicochemical characteristics and Gene location of BBX proteins of A. thaliana, $G$. arboreum, $G$. raimondii, G. hirsutum and G. barbadense. The pl and MW were computed by ExPASy website. Subcellular localizations of BBX proteins were predicted by protcomp version 9.0 server. Gene locus information for BBXS in G. arboreum, G. raimondii, G. hirsutum and G. barbadense was obtained from gene annotation.

Additional file 3: Table S3. Ka/Ks ratios and duplicate types of gene pairs between the A and D subgenomes of allotetraploid cottons and their corresponding ancestral A and D diploid genomes, respectively. The homologous gene pairs were identified by the results of BLAST and collinearity analysis. When both $\mathrm{Ka}$ and $\mathrm{Ks}$ were equal to $0, \mathrm{Ka} / \mathrm{Ks}$ was considered equal to 1 . When only $K s$ was equal to 0 , it was marked as $K a>>K s$. Segmental means that the gene might arise from segmental duplication.

Additional file 4: Table S4. Statistical results of phytohormone and stress response cis-acting elements in the promoter segments of BBXs. These cis-acting elements were identified using PlantCARE software with the upstream 2000-bp sequences of cotton BBXs.

Additional file 5: Table S5. Primer pairs used for gene clone in yeast two-hybrid assay

\section{Authors' contributions}

HTW and ZF conceived and designed the study and prepared the manuscript. ZF, ML, YL, and XY performed the experiments. HW, LM, XF, and $J L$ assisted with the analysis and interpretation of the data. SY participated in the design of the experiments and provided a critical review. All authors have read, edited, and approved the current version of the manuscript.

\section{Funding}

This work was supported by National Natural Science Foundation of China (32072112)Central Public-interest Scientific Institution Basal Research Fund (1610162020010307), Agricultural Science and Technology Innovation Program of Chinese Academy of Agricultural Sciences.

\section{Availability of data and materials}

The data included in this article and the additional files are available. The transcriptome datasets of G. hirsutum TM-1 are under the accession number in PRJNA490626 NCBI.

\section{Declarations}

Ethics approval and consent to participate Not applicable.

\section{Consent for publication}

Not applicable.

\section{Competing interests}

The authors declare that they have no competing interests.

\section{Author details}

State Key Laboratory of Cotton Biology, Institute of Cotton Research of CAAS, Anyang 455000, China. ${ }^{2}$ Zhengzhou Research Base, State Key Laboratory of Cotton Biology, Zhengzhou University, Zhengzhou, China.

Received: 1 February 2021 Accepted: 3 June 2021

Published online: 12 June 2021

\section{References}

1. Riechmann JL, Heard J, Martin G, Reuber L, Jiang C, Keddie J, Adam L, Pineda O, Ratcliffe OJ, Samaha RR et al: Arabidopsis transcription factors: genome-wide comparative analysis among eukaryotes. Science 2000, 290(5499):2105-2110.

2. Zhao T, Wu T, Zhang J, Wang Z, Pei T, Yang H, Li J, Xu X: Genome-wide analyses of the genetic screening of $\mathrm{C} 2 \mathrm{H} 2$-type zinc finger transcription factors and abiotic and biotic stress responses in tomato (Solanum iycopersicum) based on RNA-Seq data. Front Genet 2020, 11:540.

3. Khanna R, Kronmiller B, Maszle DR, Coupland G, Holm M, Mizuno T, Wu SH: The Arabidopsis B-boxzinc finger family. Plant Cell 2009, 21(11):3416-3420.

4. Gangappa SN, Botto JF: The BBX family of plant transcription factors. Trends Plant Sci 2014, 19(7):460-470.

5. Griffiths S, Dunford RP, Coupland G, Laurie DA: The evolution of CONSTANSlike gene families in barley, rice, and Arabidopsis. Plant Physiol 2003, 131(4): 1855-1867.

6. Yan H, Marquardt K, Indorf M, Jutt D, Kircher S, Neuhaus G, RodriguezFranco M: Nuclear localization and interaction with COP1are required for STO/BBX24 function during photomorphogenesis. Plant Physiol 2011, 156(4): 1772-1782.

7. Gendron JM, Pruneda-Paz JL, Doherty CJ, Gross AM, Kang SE, Kay SA: Arabidopsis circadian clock protein, TOC1, is a DNA-binding transcription factor. Proc Natl Acad Sci U S A 2012, 109(8):3167-3172.

8. Gonzalez-Schain ND, Diaz-Mendoza M, Zurczak M, Suarez-Lopez P: Potato CONSTANS is involved in photoperiodic tuberization in a graft-transmissible manner. Plant J 2012, 70(4):678-690.

9. Lee YS, Jeong DH, Lee DY, Yi J, Ryu CH, Kim SL, Jeong HJ, Choi SC, Jin P, Yang J et al: OsCOL4is a constitutive flowering repressor upstream of Ehd 1 and downstream of OsphyB. Plant J 2010, 63(1):18-30.

10. Ding L, Wang S, Song ZT, Jiang Y, Han JJ, Lu SJ, Li L, Liu JX: Two B-BoX domain proteins, $B B \times 18$ and $B B \times 23$, interact withELF3 and regulate thermomorphogenesis in Arabidopsis. Cell Rep 2018, 25(7):1718-1728 e1714.

11. Putterill J, Robson F, Lee K, Simon R, Coupland G: The CONSTANS gene of Arabidopsis promotes flowering and encodes a protein showing similarities to zinc finger transcription factors. Cell 1995, 80(6):847-857.

12. Robson F, Costa MM, Hepworth SR, Vizir I, Pineiro M, Reeves PH, Putterill J, Coupland G: Functional importance of conserved domains in the floweringtime gene CONSTANS demonstrated by analysis of mutant alleles and transgenic plants. Plant J 2001, 28(6):619-631.

13. Yang Y, Ma C, Xu Y, Wei Q, Imtiaz M, Lan H, Gao S, Cheng L, Wang M, Fei Z et al: A zinc finger protein regulates flowering time and abiotic stress tolerance in chrysanthemum by modulating gibberellin biosynthesis. Plant Cell 2014, 26(5):2038-2054

14. Samach A, Onouchi H, Gold SE, Ditta GS, Schwarz-Sommer Z, Yanofsky MF, Coupland G: Distinct roles of CONSTANS target genes in reproductive development of Arabidopsis. Science 2000, 288(5471):1613-1616.

15. Valverde F, Mouradov A, Soppe W, Ravenscroft D, Samach A, Coupland G: Photoreceptor regulation of CONSTANS protein in photoperiodic flowering. Science 2004, 303(5660):1003-1006

16. Datta S, Hettiarachchi GH, Deng XW, Holm M: Arabidopsis CONSTANS-LIKE3is a positive regulator of red light signaling and root growth. Plant Cell 2006, 18(1):70-84

17. Cheng XF, Wang ZY: Overexpression ofCOL9, a CONSTANS-LIKE gene, delays flowering by reducing expression of $\mathrm{CO}$ and $\mathrm{FT}$ in Arabidopsis thaliana. Plant J 2005, 43(5):758-768.

18. Tripathi $\mathrm{P}$, Carvallo M, Hamilton EE, Preuss S, Kay SA: Arabidopsis B-BOX32 interacts with CONSTANS-LIKE3 to regulate flowering. Proc Natl Acad Sci U S A 2017, 114(1):172-177.

19. Hassidim M, Harir Y, Yakir E, Kron I, Green RMJP. Over-expression of CONSTANS-LIKE 5can induce flowering in short-day grown Arabidopsis. Planta. 2009:230(3):481-91. 
20. Nagaoka S, Takano T: Salt tolerance-related protein STO binds to a Myb transcription factor homologue and confers salt tolerance in Arabidopsis. J Exp Bot 2003, 54(391):2231-2237.

21. Wang Q, Zeng J, Deng K, Tu X, Zhao X, Tang D, Liu X: DBB1a, involved in gibberellin homeostasis, functions as a negative regulator of blue lightmediated hypocotyl elongation in Arabidopsis. Planta 2011, 233(1):13-23.

22. Fan XY, Sun Y, Cao DM, Bai MY, Luo XM, Yang HJ, Wei CQ, Zhu SW, Sun Y, Chong K et al: BZS1, a B-box protein, promotes photomorphogenesis downstream of both brassinosteroid and light signaling pathways. Mol Plant 2012, 5(3):591-600.

23. Chu Z, Wang X, Li Y, Yu H, Li J, Lu Y, Li H, Ouyang B: Genomic organization, phylogenetic and expression analysis of the B-BOX gene family in tomato. Front Plant Sci 2016, 7:1552.

24. Cao Y, Han Y, Meng D, Li D, Jiao C, Jin Q, Lin Y, Cai Y: B-BOXgenes: genomewide identification, evolution and their contribution to pollen growth in pear (Pyrus bretschneideri rehd.). BMC Plant Biol 2017, 17(1):156.

25. Liu X, Li R, Dai Y, Chen X, Wang X: Genome-wide identification and expression analysis of the $B$-boxgene family in the Apple (Malus domestica Borkh.) genome. Mol Genet Genomics 2018, 293(2):303-315.

26. Li F, Fan G, Lu C, Xiao G, Zou C, Kohel RJ, Ma Z, Shang H, Ma X, Wu J et al: Genome sequence of cultivated upland cotton (Gossypium hirsutum TM-1) provides insights into genome evolution. Nat Biotechnol 2015, 33(5):524-530

27. Yan B, Hou J, Cui J, He C, Li W, Chen X, Li M, Wang W. The effects of endogenous hormones on the flowering and fruiting of glycyrrhiza uralensis. Plants (Basel). 2019;8(11):519.

28. Zhang $X$, Wang $C$, Pang C, Wei H, Wang H, Song M, Fan S, Yu S. Characterization and functional analysis of PEBP family genes in upland cotton (Gossypium hirsutum L.). PLoS One 2016, 11 (8):e0161080

29. Zhang X, Wei J, Fan S, Song M, Pang C, Wei H, Wang C, Yu S: Functional characterization of GhSOCl and GhMADS42 homologs from upland cotton (Gossypium hirsutum L.). Plant Sci 2016, 242:178-186.

30. Li J, Fan SL, Song MZ, Pang CY, Wei HL, Li W, Ma JH, Wei JH, Jing JG, Yu SX: Cloning and characterization of a FLO/LFY ortholog in Gossypium hirsutum L. Plant Cell Rep 2013, 32(11):1675-1686.

31. Cheng S, Chen P, Su Z, Ma L, Hao P, Zhang J, Ma Q, Liu G, Liu J, Wang H et al: High-resolution temporal dynamic transcriptome landscape reveals a GhCAL-mediated flowering regulatory pathway in cotton (Gossypium hirsutum L.). Plant Biotechnol J 2021, 19(1):153-166.

32. Wei $H$, Wang $P$, Chen J, Li C, Wang Y, Yuan Y, Fang J, Leng X: Genome-wide identification and analysis of $B-B O X$ gene family in grapevine reveal its potential functions in berry development. BMC Plant Biol 2020, 20(1):72.

33. RDWJARoE S. Systematics: pathways, mechanisms, and rates of polyploid formation in flowering plants. Annu Rev Ecol Syst. 1998;29:467-501.

34. Paterson AH, Wendel JF, Gundlach H, Guo H, Jenkins J, Jin D, Llewellyn D, Showmaker KC, Shu S, Udall J et al: Repeated polyploidization of Gossypium genomes and the evolution of spinnable cotton fibres. Nature 2012, 492(7429):423-427.

35. Zhu YX, Li FG: The Gossypium raimondii genome, a huge leap forward in cotton genomics. J Integr Plant Biol 2013, 55(7):570-571.

36. Park HY, Lee SY, Seok HY, Kim SH, Sung ZR, Moon YH: EMF1 interacts with EIP1, EIP6 or EIP9 involved in the regulation of flowering time in Arabidopsis. Plant Cell Physiol 2011, 52(8):1376-1388.

37. Zhu T, Liang C, Meng Z, Sun G, Meng Z, Guo S, Zhang R: CottonFGD: an integrated functional genomics database for cotton. BMC Plant Biol 2017, 17(1):101.

38. Reiser L, Subramaniam S, Li D, Huala E: Using the Arabidopsis information resource (TAIR) to find information about Arabidopsis genes. Curr Protoc Bioinformatics 2017, 60:1 11 11-11 1145.

39. Finn RD, Coggill P, Eberhardt RY, Eddy SR, Mistry J, Mitchell AL, Potter SC, Punta M, Qureshi M, Sangrador-Vegas A et al: The Pfam protein families database: towards a more sustainable future. Nucleic Acids Res 2016, 44(D1): D279-285

40. Camacho C, Coulouris G, Avagyan V, Ma N, Papadopoulos J, Bealer K, Madden TL: BLAST+: architecture and applications. BMC Bioinformatics 2009, 10:421.

41. Letunic I, Doerks T, Bork P: SMART: recent updates, new developments and status in 2015. Nucleic Acids Res 2015, 43(Database issue):D257-260.

42. Artimo $P$, Jonnalagedda $M$, Arnold $K$, Baratin D, Csardi G, de Castro E, Duvaud S, Flegel V, Fortier A, Gasteiger E, et al. ExPASy: SIB bioinformatics resource portal. Nucleic Acids Res. 2012;40(W1):W597-603.
43. Kumar S, Stecher G, Tamura K. MEGA7: molecular evolutionary genetics analysis version 7.0 for bigger datasets. Mol Biol Evol. 2016:33(7):1870-1874.

44. Voorrips RE: MapChart: software for the graphical presentation of linkage maps and QTLs. J Hered 2002, 93(1):77-78.

45. Wang Y, Tang H, Debarry JD, Tan X, Li J, Wang X, Lee TH, Jin H, Marler B, Guo $\mathrm{H}$ et al: MCScanX: a toolkit for detection and evolutionary analysis of gene synteny and collinearity. Nucleic Acids Res 2012, 40(7):e49.

46. Krzywinski M, Schein J, Birol I, Connors J, Gascoyne R, Horsman D, Jones SJ, Marra MA: Circos: an information aesthetic for comparative genomics. Genome Res 2009, 19(9):1639-1645.

47. Chen C, Chen H, Zhang Y, Thomas HR, Frank MH, He Y, Xia R: TBtools: An integrative toolkit developed for interactive analyses of big biological data. Mol Plant 2020, 13(8):1194-1202.

48. Hu B, Jin J, Guo AY, Zhang H, Luo J, Gao G: GSDS 2.0: an upgraded gene feature visualization server. Bioinformatics 2015, 31(8):1296-1297.

49. Lescot M, Dehais $P$, Thijs $G$, Marchal $K$, Moreau $Y$, Van de Peer $Y$, Rouze $P$, Rombauts S: PlantCARE, a database of plant cis-acting regulatory elements and a portal to tools for in silico analysis of promoter sequences. Nucleic Acids Res 2002, 30(1):325-327.

50. Zhang T, Hu Y, Jiang W, Fang L, Guan X, Chen J, Zhang J, Saski CA, Scheffler BE, Stelly DM et al: Sequencing of allotetraploid cotton (Gossypium hirsutum L. acc. TM-1) provides a resource for fiber improvement. Nat Biotechnol 2015, 33(5):531-537.

\section{Publisher's Note}

Springer Nature remains neutral with regard to jurisdictional claims in published maps and institutional affiliations.
Ready to submit your research? Choose BMC and benefit from:

- fast, convenient online submission

- thorough peer review by experienced researchers in your field

- rapid publication on acceptance

- support for research data, including large and complex data types

- gold Open Access which fosters wider collaboration and increased citations

- maximum visibility for your research: over $100 \mathrm{M}$ website views per year

At $\mathrm{BMC}$, research is always in progress.

Learn more biomedcentral.com/submissions 